\title{
Agroindustria y algodón en el valle de Mexicali. La Compañía Industrial Jabonera del Pacífico
}

\section{Agro-industry and cotton in the Mexicali valley. The Compañía Industrial Jabonera del Pacífico}

Aidé Grijalva*

Resumen

El valle de Mexicali surgió a principios del siglo xx como parte de la expansión de la frontera agrícola del suroeste de Estados Unidos. No se puede explicar esto sin la participación de capitalistas estadunidenses que se adueñaron de la tierra y del agua del valle de Mexicali, estableciendo las bases de un desarrollo agroindustrial que giró alrededor del cultivo del algodón. Una empresa, subsidiaria de la Anderson, Clayton \& Company, tuvo un papel relevante en ese proceso, logrando convertir al valle de Mexicali en uno de los principales productores de algodón de México.

Palabras clave: algodón, tierra, agua, agroindustria.
Abstract

The Mexicali Valley emerged in the early twentieth century as part of the expansion of the agricultural frontier in the southwestern United States. You can not explain this without the participation of American capitalists who took over the land and water of Mexicali Valley and laid the foundations of an agribusiness development around the cultivation of cotton. A company, a subsidiary of Anderson, Clayton \& Company, played an important role in this process, making turning the Mexicali Valley in one of the largest producers of cotton in Mexico.

Keywords: cotton, land, water, agribussines.

Recibido el 4 de junio de 2013.

Aprobado el 20 de enero de 2014.

* Investigadora del Instituto de Investigaciones Sociales de la Universidad Autónoma de Baja California. Miembro del Cuerpo Académico de Estudios Sociales (CADEs). Correo electrónico: aidel@uabc.edu.mx 


\section{Introducción}

El propósito de este trabajo es contribuir al mejor conocimiento de lo que Aboites denomina el "episodio algodonero" en el norte de México (Aboites, 2013, p. 9) y, específicamente, algunas de las particularidades de este fenómeno en la ciudad y el valle de Mexicali. A pesar de existir entre los viejos mexicalenses una nostalgia por la época en la que se "barría el dinero con una escoba", en referencia a una etapa caracterizada por la prosperidad económica, con el algodón como el pivote de la misma, no hay estudios que integren los diferentes elementos que permitieron esa bonanza local, misma que no fue aislada sino que formó parte de un fenómeno regional. Tal como lo señala el propio Aboites, la historia del algodón mexicano del siglo xx todavía está por hacerse (Aboites, 2013, pp. 25-26) y este ensayo pretende ser un paliativo a ese pendiente historiográfico mediante la descripción a grandes rasgos de una empresa que lideró durante varias décadas el cultivo y la industrialización de dicha fibra en el valle de Mexicali.

Para la exposición de los resultados de esta modesta indagación basada en fuentes secundarias, se optó por el orden temático, aunque al interior de cada apartado hemos tratado de seguir una exposición de índole cronológica. Esto no es casual. Estamos ante un rompecabezas del cual faltan aún piezas claves, pues en la segunda década del siglo xxi la bibliografía sobre las desventuras y los desasosiegos del algodón en el valle de Mexicali aún sigue siendo escasa. Historiografía de la indiferencia en términos de libros y artículos publicados sobre el algodón, la denomina un experto en el tema (Aboites, 2013, p. 22).

El gran interés por investigar los temas relacionados con la estructura agraria del valle de Mexicali, en virtud de que durante casi la primera mitad del siglo xx la mayor parte de la tierra de dicha región fue propiedad de un consorcio estadunidense, propició pesquisas alrededor de la compañía terrateniente y sobre el reparto agrario llevado a cabo en 1937, principio del fin de dicho monopolio, acaparando así la atención de los estudiosos sobre el pasado del lugar. En esto tuvo un papel fundamental la ideología del nacionalismo revolucionario que hizo del reparto agrario una de sus principales premisas, desplazando el interés por otros temas de gran relevancia histórica como son los del agua, el algodón, la migración, el impacto demográfico y el desarrollo urbano, entre otros. 
Por otro lado, la ausencia de fuentes primarias favoreció interpretaciones erróneas del auténtico papel que tuvo la corporación dueña de las tierras del valle de Mexicali, atribuyéndole un papel protagónico y crucial en el desarrollo económico, al punto de que algunos autores llegaron a afirmar que durante más de tres décadas ésta "controló el desarrollo de la producción agrícola y agroindustrial del valle de Mexicali” (Anguiano, 1992, p. 143). Las más recientes investigaciones de índole histórica cuestionan esta visión, pues al parecer la empresa latifundista, iniciadora del cultivo algodonero en el lugar, transfirió su liderazgo económico a otras empresas agroindustriales.

Lo cierto es que en ese extenso valle localizado en la frontera norte de México, en el estado de Baja California, durante buena parte del siglo xx existió un complejo agroindustrial de gran envergadura, dedicado al despepite y a la industrialización de la semilla del algodón, que llevó el nombre de Compañía Industrial Jabonera del Pacífico, mejor conocida en el ámbito local como La Jabonera.

Desde su fundación en 1925 y hasta su cierre en el año de 1973, esta empresa tuvo un papel crucial en el desarrollo agrícola del valle de Mexicali y, como veremos más adelante, mucho más que el atribuido a la dueña de las tierras. No fue la única empresa de esta naturaleza, aunque nos atrevemos a afirmar que sí fue la más importante. Compartió con otras corporaciones del ramo las desventuras y los desasosiegos por los altibajos del precio internacional del algodón y los problemas derivados del cultivo del mismo.

Con el cierre de La Jabonera terminó una etapa de la historia de la ciudad y el valle de Mexicali, y aunque hoy algunos agricultores aún siembran algodón y existen todavía algunas despepitadoras en el lugar, la época en la que las tierras del valle de Mexicali se pintaban de blanco pues estaban dedicadas al monocultivo de lo que se llamó "oro blanco", forma parte del pasado reciente.

\section{Los primeros pasos}

El surgimiento del valle y la ciudad de Mexicali en los albores del siglo xx fue consecuencia de la derivación en territorio mexicano de las aguas del 
Río Colorado, pues con el propósito de conducir el líquido a la parte sureste del estado de California, específicamente al Valle Imperial, se desvió agua a través del cauce de un ramal del Colorado, conocido como canal del Álamo (Berumen, 2013, p. 113).

Ubicado en el noreste de la península de Baja California, el valle de Mexicali colinda por el este con el estado mexicano de Sonora, y por el norte con el estadunidense de California. Este valle se formó con las tierras del delta del Río Colorado ya que durante miles de años el entonces impetuoso río depositó en este lugar el material que acarreaba en su prolongada travesía, pues después de nacer en las Montañas Rocallosas realiza un largo recorrido antes de morir en el golfo de California, siendo considerado el cuerpo de agua más largo de la vertiente del Océano Pacífico. La gran cantidad de sedimentos depositados a lo largo de milenios explica la fertilidad de dichas tierras. El delta mexicano del Río Colorado se extiende hasta Sonora, en donde recibe el nombre de San Luis Río Colorado, pero es parte del valle de Mexicali y junto con el californiano Valle Imperial forma una unidad geográfica. Son el mismo delta, separados ahora por divisiones políticas (Grijalva, 2008, p. 13) (figura 1).

A principios del siglo xx la porción bajacaliforniana de este delta fue adquirida por un grupo de inversionistas estadunidenses liderados inicialmente por Harrison Gray Otis y, después, por su yerno, Harry Chandler. Otis y Chandler, destacados empresarios dedicados a la especulación de las bienes raíces en el suroeste de Estados Unidos, eran, además, propietarios del influyente periódico Los Angeles Times (Kerig, 2001, p. 65-70).

Con el fin de adquirir la parte mexicana de esa región deltaica, aledaña a la desembocadura del Río Colorado en el golfo de California, en 1902 Otis y Chandler organizaron la Colorado River Land Company, S. A., y mediante una serie de operaciones de compra-venta, adquirieron las más de 350000 hectáreas que conformaban dicha región (Hendricks, 1996, pp. 155-162). Esta compañía permaneció en el lugar hasta el año de 1946, cuando vendió al gobierno mexicano las más de 200000 hectáreas que aún poseía en el mencionado valle, después de que en 1937 Lázaro Cárdenas, entonces presidente de México, en un hecho conocido en los anales de la historia local como el "Asalto a las Tierras", le expropiara cerca de 102000 hectáreas de tierra abiertas al cultivo en ese momento (Kerig, 2001, pp. 282-285). 
Figura 1

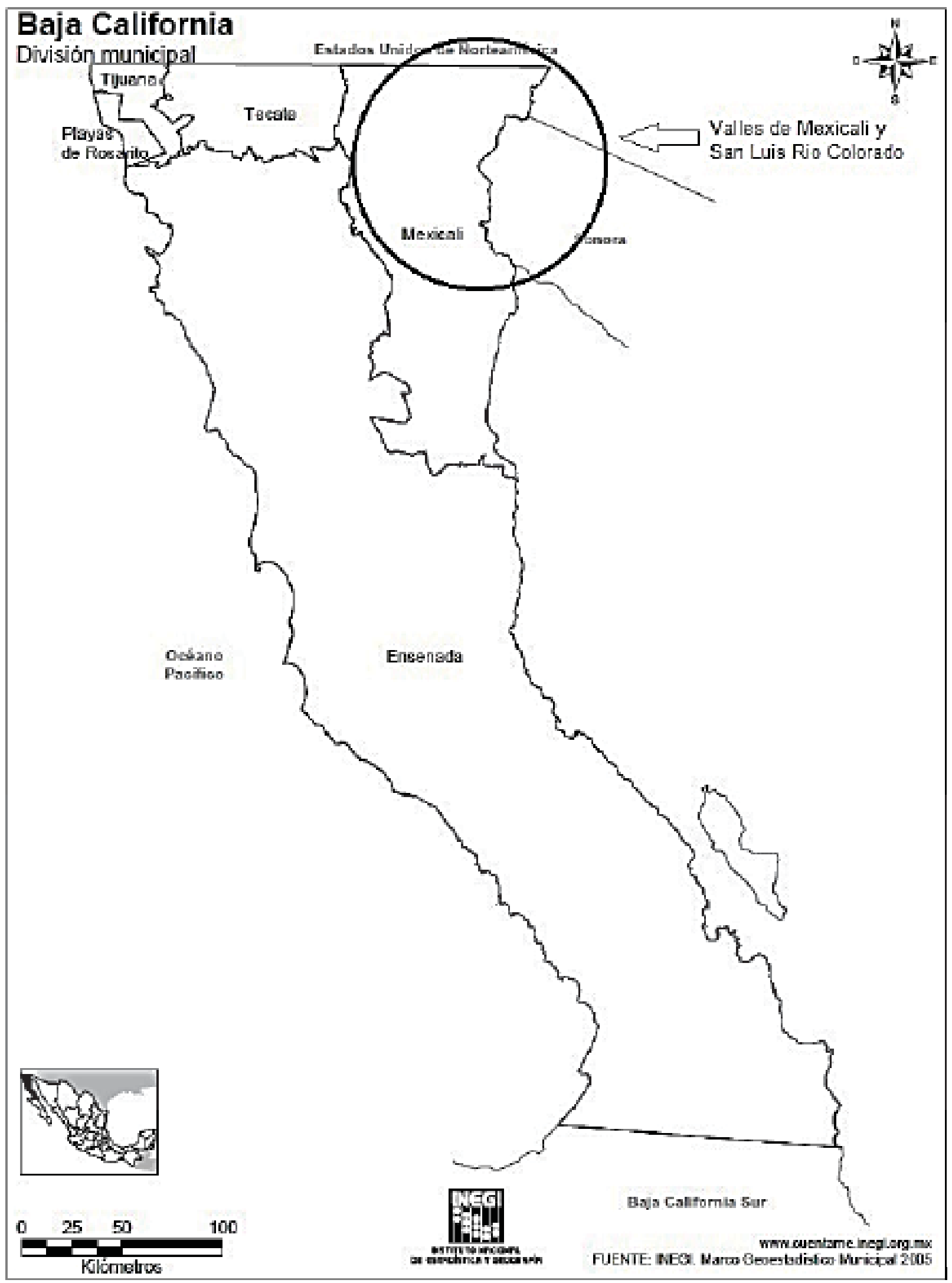


Si bien los propietarios estadunidenses de estas tierras habían iniciado el cultivo del algodón en el delta mexicano del Río Colorado, es importante aclarar que ése no era el propósito inicial, sino establecer un rancho ganadero (Kerig, 2001, pp. 82-83). Sin embargo, la demanda de algodón, resultado de la conflagración mundial de 1914-1918, originó que los propietarios de las tierras del delta mexicano del Colorado optaran por establecer su cultivo, tal como ya se hacía en el vecino Valle Imperial. La primera cosecha de este producto se registró en 1912, con 12 hectáreas sembradas y un resultado de 15 pacas. La superficie cosechada llegó a las 42483 hectáreas en 1919 (Aboites, 1991a, p. 8) y para el ciclo 1920-1921 se obtuvieron 79200 pacas en 50000 hectáreas irrigadas (López, E., 1977, p. 55). ${ }^{1}$

A diferencia de otras partes del país, el aislamiento del valle de Mexicali respecto del resto del macizo continental mexicano propició que el llamado "periodo revolucionario" (1910-1920) fuera de una gran prosperidad agrícola ${ }^{2}$ y de un importante auge de la agricultura de riego (Aboites, 1991b, p. 517). "La fase más caótica de la Revolución Mexicana fue para el norte de Baja California, por contraste, un periodo de relativa tranquilidad, crecimiento y prosperidad económica”, afirma la historiadora Dorothy P. Kerig (2001, p. 128).

Precisamente, fueron los dueños de la Colorado River Land Company, mejor conocida como "la Colorado", quienes invitaron a Juan F. Brittingham —un empresario pionero en el despepite del algodón, dueño en el norte de Durango de una fábrica dedicada a industrializar la semilla de algodón, elaborando además de nitroglicerina, ${ }^{3}$ jabones de toda índole- a trasladarse a Mexicali para instalar una fábrica igual a la que éste ya tenía en Gómez Palacio, dentro de la región conocida como la Comarca Lagunera (Kerig, 2001, pp. 220-222). Detrás de este ofrecimiento estaba

1 Según Pablo Bistráin, fueron 8741 las hectáreas irrigadas en 1912, y para 1920 las hectáreas sembradas ascendían a 76890 (Bistráin, 1953, p. 64).

${ }^{2}$ En ese periodo el punto más alto fue el ciclo agrícola 1918-1919, cuando la cosecha de algodón alcanzó un valor de 28 millones de pesos (Aboites, 1991a, p. 8).

${ }^{3}$ Con el algodón se sintetiza ácido nítrico y ácido sulfúrico, los mismos utilizados en la elaboración de nitroglicerina. Ésta es la base del llamado "algodón pólvora", mejor conocido como pólvora sin humo. Su descubrimiento tuvo lugar a mediados del siglo xix. 
el hecho de que las despepitadoras del lugar no eran suficientes para el despepite de todo el algodón que con gran éxito se cultivaba en el valle de Mexicali en la segunda década del siglo xx.

Resultado de esta invitación fue la organización en 1925 de la Compañía Industrial Jabonera del Pacífico como una sociedad de cooperación limitada (S.C.L.). El propósito era aprovechar la semilla del algodón que se cosechaba en tierras de la Colorado River Land Company y que ésta arrendaba a agricultores, la mayoría extranjeros (chinos y japoneses) y excepcionalmente a mexicanos; o bien, "en tierras cuya producción de semilla se afecte a la sociedad posteriormente”, como señala la cláusula segunda de la escritura constitutiva de la empresa (Grijalva, 2008, p. 71).

Juan F. Brittingham se estableció en Mexicali durante cinco años. En ese tiempo construyó instalaciones muy similares a las que había erigido en Gómez Palacio, Durango, pero en 1930 traspasó sus intereses a la Anderson, Clayton. ${ }^{4}$ Para entonces La Jabonera consistía en un molino de aceite, una refinería, una bodega para la "torta" que producía el molino, el tejabán de semilla y un edificio donde estaba la jabonería. Había otro tejabán donde estaba instalada una caldera para surtir de vapor al molino y posiblemente otro para cubrir otra caldera para la refinería y la jabonería. Todos estos edificios tenían estructuras de acero prefabricadas y techos de lámina corrugada y galvanizada de buena calidad que, según el testimonio de un ex funcionario, sirvieron durante los años que duró La Jabonera (Grijalva, 2008, pp. 69-70).

La Anderson, Clayton adquirió las dos terceras partes de las acciones de La Jabonera, con lo que se convirtió en prácticamente la dueña de esa empresa. Estableció en el valle de Mexicali un sistema de crédito agrícola mediante el cual habilitaba a los agricultores para que contaran con el financiamiento necesario para sembrar sus tierras, desde su preparación hasta la cosecha del cultivo. La condición era que sembraran algodón y que éste, en hueso, fuera entregado a la empresa refaccionadora, que a su vez aseguraba la materia prima que despepitaba en sus instalaciones y la semilla que posteriormente industrializaba en sus molinos.

${ }^{4}$ El nombre de la compañía era Anderson, Clayton \& Company. Así aparecía en los membretes de la empresa. En el interior de México fue conocida como "la Clayton” y su nombre oficial era Anderson, Clayton \& Company, S. A. Las siglas eran ACCO. 
Al lado de La Jabonera original había otras empresas dedicadas al despepite del algodón, como la Mexican Chinese Ginning Company, S. A., después llamada Despepitadora de Mexicali —mejor conocida como La Chinesca—, ${ }^{5}$ y la Compañía Algodonera de Baja California, S. A., pionera en la región de esa actividad productiva. ${ }^{6}$ Junto con ellas, otras empresas del ramo, siguiendo el cultivo de esta malvácea, se establecieron en el lugar posteriormente y coadyuvaron para que el valle de Mexicali fuera, a mediados del siglo xx, uno de los más importantes productores de algodón en la república mexicana, sólo superado por la Comarca Lagunera. Tal fue el caso de las Empresas Hohenberg, de la Despepitadora Mc Fadden, de la Algodonera del Valle, de Industrias Unidas del Colorado y de la Productora Agrícola (ambas de Esteve Hermanos); de la Despepitadora La Popular, de Algodones Universales, de Algodoneros Unidos, de la Algodonera Internacional, de la Despepitadora Oro Blanco, de las Empresas Longoria y de la Empresa de Rafael Leyva Castro y socios (Grijalva, 2008, p. 148) (figura 2).

\section{La competencia mundial por el algodón}

La tendencia general para producir algodón tanto en el suroeste de Estados Unidos como en el norte de México durante este periodo coincide con lo que se denominó en Estados Unidos la "Irrigation Era", que propició el financiamiento gubernamental a proyectos hidráulicos de gran envergadura (Colby y Jacobs, 2007, pp. 12-16). El propósito de esta iniciativa era "hacer florecer al desierto americano" (Walsh, 2007, p. 101), dentro del contexto de la lucha que libraron durante los primeros años del siglo xx Gran Bretaña y Estados Unidos por el control mundial de la industria textil (López, E., 1977, p. 52).

${ }^{5}$ Fue establecida en 1919 por James B. Hoffman y Teophilus J. West. Contaba con cuatro despepitadoras, empleaba a 75 trabajadores y tenía capacidad para producir 350 pacas en 24 horas. Al parecer esas instalaciones fueron las más grandes de su ramo en esa época (Grijalva, 2008, p. 149).

${ }^{6}$ Aparentemente fue la primera despepitadora en el valle de Mexicali, filial de la Globe Grain and Milling Company de Los Ángeles, California (Aboites, 1991, p. 519), mejor conocida como la Globe Mills, habiendo sido establecida en 1916. Tenía dos o más baterías de despepitadoras y contaba con un pequeño molino de aceite (Grijalva, 2008, p.149). 
Figura 2. Localización de las despepitadoras de algodón en los valles de Mexicali y San Luis. Circa 1970

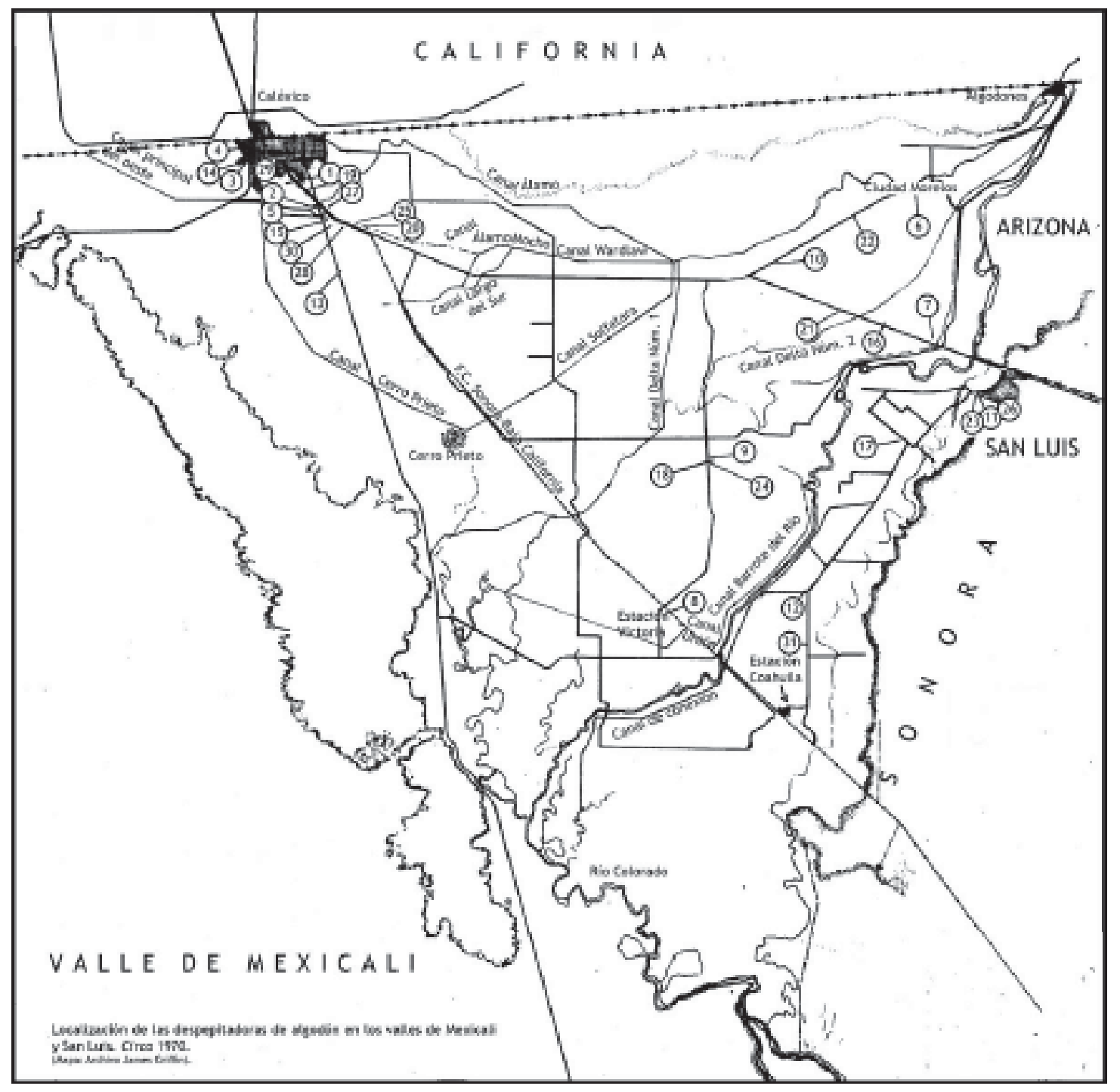

1. Algodonera del Valle

2. Algodonera de Baja California

3. Empresas Hohenberg

4. Compañía Industrial del Pacífico (La Jabonera)

5. Despepitadora del Pacífico, Planta Pacífico (La Jabonera)

6. Despepitadora del Pacífico, Planta Morelos (La Jabonera)

7. Despepitadora del Pacífico, Planta Río Colorado (La Jabonera)

8. Despepitadora del Pacífico, Planta Victoria (La Jabonera)

9. Despepitadora del Pacífico, Planta Crucero (La Jabonera)

10. Algodonera Delta, Planta Tecolote (La Jabonera)

11. Algodonera de San Luis (La Jabonera)

12. Despepitadora del Pacífico, Planta Coahuila (La Jabonera)

13. Despepitadora Mc Fadden

14. Despepitadora de Mexicali (La Chinesca)

15. Algodonera Internacional (Planta Mexicali)

16. Algodonera Internacional (Planta Hermosillo)

Fuente: Archivo James Griffin.
17. Algodonera Internacional (Planta Moctezuma)

18. Algodonera Internacional

19. Despepitadora Popular

20. Empresas Longoria (Planta Palaco)

21. Empresas Longoria (Planta Tabasco)

22. Empresas Longoria (Planta Paredones)

23. Empresas Longoria (Planta San Luis)

24. Empresas Longoria (Planta Veracruz)

25. Productora Agrícola (Esteve Hermanos)

26. Industrias Unidas del Colorado

(Esteve Hermanos)

27. Algodoneros Unidos

28. Despepitadora Oro Blanco

29. Banco Nacional de Crédito Ejidal

30. Algodones Universales

31. Empresa de Rafael Leyva Castro y socios 
La feroz competencia entre ambos contendientes ocasionó que Gran Bretaña realizara una campaña sin precedentes para introducir el cultivo del algodón en sus dominios, colonias y protectorados como Nigeria, Uganda, Rhodesia, Sudáfrica, Tanganica, Punjab y el Sudán anglo-egipcio, con el objetivo de no depender más del algodón estadunidense (Case, 1929, p. 343). No obstante, antes de la Primera Guerra Mundial Inglaterra aún importaba millones de pacas de algodón procedentes de Estados Unidos. Para el periodo comprendido entre 1913 y 1938, las exportaciones de algodón en la industria británica algodonera declinaron de manera drástica pues la recesión mundial y la caída de los ingresos de las naciones productoras redujeron la demanda de los textiles británicos (Singleton, 1998, p. 62).

En cambio, Estados Unidos implementó con éxito una estrategia para impulsar el cultivo del algodón, realizando cuantiosas inversiones en la construcción de sistemas de riego, instalación de plantas compresoras, despepitadoras, almacenes y en equipos de carga y de transporte, necesarios para el movimiento del algodón, así como en la apertura de vías de comunicación. Para la década de 1920, Estados Unidos era el mayor productor de algodón, por encima de todos los demás países juntos (López, E., 1977, pp. 52-53). El Cotton Belt fue avanzando desde el Este hacia el Oeste, incluyendo Alabama, Georgia, Louisiana, Mississippi, Misuri, las dos Carolinas, Oklahoma, Tennessee, Nuevo México, Texas y Arizona, hasta llegar a California (Grijalva, 2008, p. 116), con toda la región deltaica del Río Colorado. En medio de esta situación mundial se iniciaron las obras para aprovechar las aguas del Río Colorado para el riego de las tierras del Valle Imperial, en donde empezó el cultivo del algodón en 1906 (Musoke y Olmstead, 1982, p. 386).

Esto explica en gran medida por qué, a partir de la segunda década del siglo xx, el algodón dominó la agricultura de riego en el norte de México, al punto que en esta parte del país se producía 95\% del algodón del país, dando lugar a una relocalización geográfica del mencionado cultivo (Aboites, 1991). Surgieron así lo que Casey Walsh denomina "sociedades fronterizas algodoneras binacionales en las áreas fronterizas," como fue el caso de los valles de Mexicali e Imperial (Walsh, 2007, p. 101). 


\section{Reorganización del agua y la tierra en el valle de Mexicali}

No sólo la tierra, sino también el agua era controlada por un grupo de inversionistas extranjeros. La Compañía de Terrenos y Aguas de la Baja California — subsidiaria del Imperial Irrigation District, empresa estadunidense encargada de la distribución de las aguas en el Valle Imperialera la propietaria del canal del Álamo, el ramal del Río Colorado que desviaba el agua hacia dicho valle californiano, así como de una importante red de canales de conducción y distribución del líquido en la región (Rubio, 2007, p. 112).

Mediante remate, esta compañía había obtenido una concesión por 50 años para la distribución y venta de las aguas del Río Colorado derivadas en territorio mexicano: el permiso fue otorgado en 1904 por el gobierno de México a una empresa de irrigación denominada Sociedad de Irrigación y Terrenos de la Baja California. ${ }^{7}$ Esta situación persistió incluso después de la inauguración en 1940 del Canal Todo Americano, que cortó la dependencia de los agricultores del Valle Imperial del agua proveniente del canal del Álamo localizado en territorio mexicano, y de la firma del Tratado de Aguas de México con Estados Unidos el 3 de febrero de 1944 (Hundley, 2000, pp. 152-153, 178), e incluso después de la entrada en funcionamiento de la presa Morelos en septiembre de 1950 (Rubio, 2007, pp. 105-111).

Desde entonces, la presa Morelos deriva las aguas del Río Colorado a las que México tiene derecho por el mencionado tratado de 1944. Este hecho permitió la adecuada operación del Distrito de Riego del Río Colorado núm. 14, creado en $1938^{8}$ como parte de la Comisión Nacional de Irrigación (Cárdenas, 1962, p. 54), abriéndose una extensa red de canales para distribuir adecuadamente entre los ejidos y las colonias del valle de

${ }^{7}$ El 17 de mayo de 1904, Manuel González Cossío, titular de la Secretaría de Fomento, Colonización e Industria, celebró un contrato con el apoderado de la Sociedad de Irrigación y Terrenos de la Baja California, autorizándolo para que por el "canal que ha construido en territorio mexicano" condujera hasta $284 \mathrm{~m}^{3}$ por segundo de agua del Río Colorado (Cárdenas, 1962, p. 20).

${ }^{8}$ El acuerdo del Ejecutivo Federal del 23 de agosto de 1938 creó el Distrito de Riego del Río Colorado y le otorgó a la Comisión Nacional de Irrigación el control, la conservación y el acondicionamiento de las obras de irrigación y la distribución de los volúmenes de agua (Cárdenas, 1962, p. 54). 
Mexicali el agua del río derivada a través de la presa Morelos, o la obtenida mediante la explotación de pozos (Rubio, 2007, pp. 119-127).

La empresa dueña del permiso para derivar agua del Río Colorado tuvo un importante papel en la expansión de la frontera agrícola al interior del delta mexicano del Río Colorado. Durante las primeras décadas del siglo xx, el ritmo de crecimiento de las tierras cultivadas fue establecido por el de la construcción de canales, diques, bordos de defensa, represas y bocatomas realizados por la mencionada empresa de irrigación, permitiendo la incorporación de nuevas tierras al área de riego, en especial en el Valle Imperial (Berumen, 2013). La Compañía de Terrenos y Aguas siguió sus operaciones hasta 1961, cuando el gobierno mexicano aceptó pagarle una indemnización por las obras hidráulicas realizadas en el valle de Mexicali (López, A., 1961).

En 1946, poco tiempo después de la firma del Tratado de Aguas, la Colorado River Land Company vendió al gobierno de México la gran cantidad de tierra que aún poseía en el valle de Mexicali (Herrera, 2002, pp. 185-191). Al ser recuperadas por el gobierno mexicano, estas tierras, salvo excepciones, ya no fueron dadas en reparto ejidal, como lo hizo Lázaro Cárdenas en 1937, sino que ahora fueron vendidas a agricultores, a los que se les denominó "pequeños propietarios" o "colonos", términos eufemísticos, permitiendo que algunos "pequeños propietarios" tuvieran acceso a un ilimitado número de hectáreas, al poner a hijos y familiares como dueños de las tierras. "Diversos y variados son los medios para la simulación en la división de latifundios [...] En esta farsa juegan un importante papel los familiares y amigos íntimos del verdadero dueño de la tierra", señala un estudioso de la cuestión agraria en el valle de Mexicali (Cárdenas, 1962, p. 49). Así, se estableció una dicotomía en la propiedad agraria del lugar: la de los ejidatarios con parcelas de 20 hectáreas $^{9}$ y la de los colonos, como se les conocía a los pequeños propietarios.

${ }^{9}$ Según Aboites, esa asombrosa superficie promedio de 20 hectáreas de riego por ejidatario es "una singularidad local por demás destacable" (Aboites, 2013, p. 172). Testigos de la época señalan que hubo una petición especial de no repetir la experiencia del reparto agrario en La Laguna, en donde la parcela ejidal fue de siete hectáreas, y que James Stone, a la sazón director de La Jabonera, había sugerido la extensión de 20 hectáreas (Dipp, 2002). 
Estos dos sucesos contribuyeron a lo que se ha bautizado como el boom algodonero del valle de Mexicali. Surgió y se desarrolló una burguesía agraria local, un sector nuevo de agricultores ricos, que aprovechó la disposición de tierra, agua y crédito agrícola para cultivar las tierras, lo que, combinado con la mecanización de algunas de las tareas requeridas para la siembra del algodón, convirtió al lugar en un polo de desarrollo, con Mexicali como el centro de gravitación económica de Baja California. Según Emilio López Zamora (1977), en 1964 la economía general bajacaliforniana dependía en $70 \%$ de la producción agrícola del valle de Mexicali, es decir, del cultivo del algodonero (López, E., 1977, p. 79).

La prosperidad del valle de Mexicali fue tan importante que propició una fuerte corriente migratoria a la región, pues la firma de un convenio entre los gobiernos de México y Estados Unidos durante la Segunda Guerra Mundial dio lugar a la llegada masiva de campesinos procedentes de todas las regiones de México que buscaban trabajar en los campos agrícolas del suroeste estadunidense. Dicho convenio, conocido con el nombre de Programa Bracero, tuvo un papel fundamental en la configuración de un mercado doméstico de fuerza de trabajo ${ }^{10}$ disponible en el noroeste de México, en especial en la zona agrícola de Baja California (Grijalva, Niño y Arriaga, 2012, pp. 229-282), fenómeno paralelo a la existencia del mencionado boom algodonero en el valle de Mexicali, pues la duración de dicho convenio binacional, de 1942 a 1964, coincide con el auge de la agricultura en el valle de Mexicali.

\section{Los empresarios del algodón}

En 1884, el estadunidense Juan F. Brittingham, junto con un compañero de escuela, Juan Terrazas, estableció una pequeña fábrica de jabón en la ciudad de Chihuahua, en el norte de México. Más tarde, Brittingham se asoció con Francisco Beltrán para consolidar varios molinos de aceite y fábricas de jabón y, en 1892, en asociación con varios propietarios de haciendas algodoneras, organizó la poderosa Compañía Industrial Jabonera de La Laguna, S. A., con oficinas principales en Gómez Palacio, Durango,

${ }^{10}$ Entendido como un mercado interno o regional de mano de obra para las faenas agrícolas. 
en el corazón de lo que se conoce como la Comarca Lagunera; el objetivo era aprovechar el aceite extraído de la semilla del algodón, además de fabricar jabón. Para el historiador Mario Cerutti, la creación en 1898 de la Compañía Industrial Jabonera de La Laguna ilustró uno de los momentos decisivos del ciclo de articulación de capitales que se concitó en buena parte del norte de México durante el porfiriato (1876-1911). A la vuelta del siglo xx, esta fábrica de aceite y jabón era considerada una de las más grandes de su género en América Latina (Barragán y Cerutti, 1993).

En 1925, a los 65 años de edad, Brittingham, acompañado de sus hijos Juan, Eduardo y Nelson, se trasladó al entonces pequeño pueblo de Mexicali, a iniciar una nueva aventura empresarial. Sus socios fueron Harry Chandler y Moses H. Sherman, accionistas mayoritarios de la Colorado River Land Company, quienes habían instalado ya su propia despepitadora, la Lower Colorado River Ginning Company (Kerig, 2001, p. 220). Éste fue el punto de partida de la nueva sociedad cuyo objetivo era "producir toda clase de aceites, glicerinas, jabones y sus derivados", para lo cual se comprometía a "establecer fábricas, talleres, plantas, expendios, bodegas y toda clase de instalaciones necesarias para la industria jabonera", según lo estipulado en la escritura constitutiva de la nueva sociedad agroindustrial (Grijalva, 2008, p. 71). Brittingham exigió tener los derechos exclusivos sobre toda la semilla del algodón cosechado en las tierras propiedad de la Colorado River Land Company (Kerig, 2001, p. 220). ${ }^{11}$

Según el testimonio del trabajador Ismael Adame (Jiménez y Dipp, 2003, pp. 46-47), el 12 de octubre de 1925, 20 obreros especializados, empleados de Juan F. Brittingham en La Laguna, fueron enviados desde Gómez Palacio, Durango, a instalar edificios y maquinaria y poner en operación el molino de aceite de la nueva empresa algodonera, la promesa para los trabajadores era regresarlos a sus casas en un año, salvo que decidieran quedarse en Mexicali. Algunas fuentes señalan que para 1928,

${ }^{11}$ El control de la semilla había sido una de las exigencias establecidas por Brittingham en la escritura constitutiva de la Compañía Industrial Jabonera de La Laguna, punto que había sido motivo de conflicto y controversia entre los agricultores-socios de esta sociedad agroindustrial. Para Brittingham tener este monopolio era fundamental (véase Cerutti, 1994, p. 107). Con estos antecedentes, se entiende que cuando repitió su experiencia en el valle de Mexicali, éste fuera un punto nodal en la carta constitutiva de la nueva empresa. 
la Compañía Industrial Jabonera del Pacífico valía 1.5 millones de dólares (Kerig, 2001, p. 232).

En febrero de 1930 Brittingham vendió sus acciones —un tercio del capital en La Jabonera - al gigante texano del algodón Anderson, Clayton, la que además adquirió un segundo tercio a otros accionistas (Kerig, 2001, pp. 222-223). Compartió con la Colorado River Land Company un tercio de las acciones de la despepitadora, mismas que, eventualmente, llegaron a pertenecer a la Fundación Mary Street Jenkins, cuando "la Colorado" abandonó el valle de Mexicali en 1946, al deshacerse de sus intereses en el lugar.

La Anderson, Clayton había sido fundada en los albores del siglo xx por William L. Clayton, quien desde joven había trabajado en la comercialización del algodón. Al principio, Clayton se asoció con sus cuñados Frank y Monroe Anderson, pero cuando éstos se retiraron del negocio, quedó al timón y en un corto periodo, gracias a la Primera Guerra Mundial, empezó a crecer con gran rapidez (Grijalva, 2008, p. 94). Dedicada al acopio, manejo, venta y distribución del algodón, para mediados de la década de 1920 Anderson, Clayton ya contaba con subsidiarias en Europa, Egipto, India y China, y para la siguiente década ya era la empresa algodonera más importante en el mundo, con despepitadoras de algodón y molinos de aceite en Estados Unidos, México, Perú, Brasil, Argentina, Paraguay y Egipto (Anderson, s/f).

Para 1945, Anderson, Clayton contaba con 223 despepitadoras, 33 molinos de aceite y 123 plantas de acopio de algodón en el mundo, llegando a ser considerada la más grande compradora, vendedora y almacenadora de algodón en hueso a escala mundial. Para mediados del siglo xx, las ventas de la Clayton en el mercado internacional llegaron a ser 3.5\% de la producción mundial de algodón (Grijalva, 2008, pp. 94 y 129).

No es difícil entender por qué cuando Brittingham decidió vender sus inversiones en el valle de Mexicali, de inmediato la Anderson, Clayton acudió como postor. Debido a la crisis mundial de 1929, que trajo como consecuencia que las ramas de la economía mexicana vinculadas al mercado internacional colapsaran, hubo incertidumbre en cuanto a la continuidad de las actividades de la Compañía Industrial Jabonera del Pacífico en el valle de Mexicali. Sin embargo, en un corto periodo ésta se recuperó y estableció un eficaz y efectivo sistema de crédito agrícola para financiar el cultivo del algodón en el lugar. 
La gran depresión económica de Estados Unidos en 1929, pudo haber sido una de las razones por las que Brittingham decidiera retirarse de la Jabonera del Pacífico, pero no hay certeza al respecto. ${ }^{12}$ En 1926, el área cultivada en el valle de Mexicali se elevó a 70130 hectáreas, aunque el año de mayores rendimientos fue 1929 (17 659 toneladas), a pesar de haberse sembrado sólo 59000 hectáreas. En 1932, se sembraron apenas 11000 hectáres con algodón (SAF, 1939, p. 87). Así, la producción bajó de manera drástica de 45456 pacas en 1930-1931, a casi 26250 en 1931-1932, e, increíblemente, a 14000 pacas en 1932-1933 (López, E., 1977, p. 63).

Ligado a lo anterior, el descenso del precio del algodón fue también radical. Hacia finales de julio de 1931, el precio de este producto bajó a 5.87 dólares por quintal, cuando en años anteriores el precio medio había sido de 20 dólares (Vargas-Lobsinger, 1999, p. 128). Entre 1931 y 1932 los agricultores del valle de Mexicali tuvieron que entregar el algodón al precio de 45 centavos de dólar la libra, cuando en la década anterior el precio había sido de entre 1.65 y 1.23 dólares (Aboites, 2013, p. 405), lo que ocasionó enormes pérdidas tanto entre los agricultores como en las empresas refaccionadoras (López, E., 1977, p. 56). Luis Aboites señala que en ninguna otra región agrícola del norte de México se registró una reducción de semejantes proporciones (Aboites, 1991b, p. 515). "La entidad más golpeada por la crisis fue Baja California” (Aboites, 1991a, p. 13).

En 1937, cuando la situación empezaba a mejorar en el valle de Mexicali, Lázaro Cárdenas expropió a "la Colorado" alrededor de 102000 hectáreas abiertas al cultivo en ese momento, y las repartió principalmente entre campesinos y jornaleros que trasladó de diferentes partes de México, a los que convirtió en ejidatarios. ${ }^{13}$ El golpe dado a la empresa latifundista, socia de la Compañía Industrial Jabonera del Pacífico, provocó una crisis, en cuya resolución Acco tuvo un papel relevante.

${ }^{12}$ Algunas versiones mencionan que problemas cardiacos lo llevaron a vender para retirarse a vivir a Los Ángeles, California, donde murió en 1940.

${ }^{13}$ Ejidatarios son los integrantes de un ejido, una forma de propiedad agraria en la que un grupo o núcleo de población recibe tierra para usos agrícolas y cuya propiedad es compartida en forma colectiva. Cada ejidatario recibe una parcela ejidal, que no debe ser menor de diez hectáreas, y existe un fundo legal, donde deben estar las residencias de los integrantes del ejido. Cada ejidatario tiene derecho a recibir un solar donde fincar su lugar de residencia. A eso se le denomina "núcleo de población ejidal”. 


\section{Hacia la consolidación agroindustrial}

Antes de la llegada de la Anderson, Clayton al valle de Mexicali, "la Colorado" había establecido un eficaz mecanismo para trabajar la tierra, a través de sistemas de arrendamiento y aparcería, en los que participaban chinos, hindúes, japoneses y, algunos mexicanos. Los fondos para adquirir semillas e implementos agrícolas, así como para la subsistencia eran proporcionados por el Banco Mercantil, propiedad de la mencionada compañía (Kerig, 2001, p. 241), con cargo al algodón crudo o en rama que se entregaba a la empresa latifundista (Dicken, 1938, p. 365).

Los aparceros tenían la obligación contractual de llevar a cabo el desmonte de las tierras y la reparación de canales de riego con sus propios recursos (López Zamora, 1977, p. 35), mientras que los dueños de "la Colorado" supervisaban cuidadosamente la siembra y el cultivo del algodón, así como la irrigación de sus tierras (Dicken, 1938, p. 365). No es difícil conjeturar el monto de las ganancias obtenidas, cuando algunos estudiosos señalan que la empresa dueña de la tierra invertía entre dos y tres millones de dólares anuales de financiamiento a los cultivadores del algodón (Kerig, 2001, p. 232).

El crédito de origen mercantil facilitó la apertura, preparación y nivelación de las tierras. Este crédito, además de facilitar la introducción de las semillas usadas en los campos algodoneros estadunidenses, permitió la incorporación de tecnologías agrícolas y agroindustriales avanzadas. El valle de Mexicali, al igual que la Comarca Lagunera, prosperó gracias al financiamiento del capital mercantil, a su especialización agrícola y al hecho de que la propiedad territorial estuviera en pocas manos (Cerutti, 1994, p. 100).

Sin embargo, cuando se llevó a cabo el reparto ejidal de las tierras, ${ }^{14}$ los campesinos beneficiados se enfrentaron al problema que representaba la

\footnotetext{
${ }^{14}$ No hay acuerdo entre los estudiosos sobre el número de ejidos y las hectáreas repartidas. Cuando se revisan los documentos oficiales sorprende constatar que el gobierno mexicano no tenía información clara de la tierra repartida ni del número de ejidos establecidos. Mientras Gabino Vázquez, el jefe del Departamento Agrario, comunicó la formación de 44 ejidos en 99924 hectáreas de tierra, el gobernador del entonces Territorio Norte de Baja California, Rodolfo Sánchez Taboada, reportaba 102375 hectáreas de tierras expropiadas y repartidas a campesinos (Kerig, 2001, p. 199).
} 
falta de experiencia en el cultivo del algodón, al venir de otras partes del país en donde sus prácticas agrícolas eran diferentes. Además, la "mexicanización” de las tierras enfrentó al gobierno cardenista con la paradoja que significaba hacerse cargo del financiamiento, la organización y la mercantilización de los cultivos en las tierras ejidales (Walsh, 2007, p. 105). A pesar de la creación en 1936 del Banco Nacional de Crédito Ejidal, la expropiación petrolera de 1938 impidió al general Lázaro Cárdenas tener acceso a créditos internacionales para apoyar al Banco Ejidal, viéndose impedido de refaccionar a los recién estrenados ejidatarios del valle de Mexicali (Jiménez y Dipp, 2003, p. 63).

Sin embargo, Cárdenas no estaba solo. Recurrió a William Clayton con el fin de que su empresa, la Anderson, Clayton, se hiciera cargo de las operaciones financieras y mercantiles del algodón mexicano, a cambio de una fuerte tajada en las ganancias (Walsh, 2007, p. 105). Fue así que "Cárdenas se embarcó en la tarea de incrementar en mil por ciento las exportaciones nacionales de algodón, teniendo a Anderson, Clayton de por medio como el gigante capitalizador de la producción de algodón”, como lo asegura Walsh (2007, p. 105).

El acuerdo firmado entre el presidente de México y Clayton a principios de 1937 amparó el convenio que el entonces subdirector del Banco Nacional de Crédito Ejidal, Julián Rodríguez Adame, establecería en 1938 con el ya director de la Compañía Industrial Jabonera del Pacífico, James Stone, para facilitar el capital para los créditos con los que durante tres años al Banco Ejidal habilitó a sus clientes ejidatarios en la siembra de algodón, trigo y alfalfa (Jiménez y Dipp, 2003, pp. 63-64). No sólo eso, la Anderson, Clayton - por medio de La Jabonera del Pacífico- auxilió al Distrito de Riego del Río Colorado con préstamos en los primeros meses de cada año, mientras llegaban las partidas presupuestales de las oficinas centrales de la Comisión Nacional de Irrigación. Esto permitió apoyar los trabajos de mantenimiento y construcción de 136 kilómetros de canales y drenes en el valle de Mexicali (Jiménez y Dipp, 2003, p. 64).

La estrategia ideada por el gobierno cardenista permitió a la Anderson, Clayton sentar sus reales en el valle de Mexicali mediante su subsidiaria; a partir de ese momento, comenzó la transformación radical de la región con un boom algodonero de repercusiones nacionales e internacionales importantes. 
Algunos aspectos coyunturales contribuyeron a esto. Por un lado, la participación de Estados Unidos en la Segunda Guerra Mundial, a partir del 8 de diciembre de 1941; por el otro, la modificación sustancial de la política agraria gubernamental a partir de la llegada de Manuel Ávila Camacho a la presidencia de México (1940-1946). La masiva redistribución de la tierra entre 1934 y 1940, durante el cardenismo, había dado como resultado un movimiento agrario totalmente dependiente del Estado mexicano. La inherente contradicción entre el ejido y el desarrollo capitalista de la agricultura mexicana dio lugar a una serie de problemas que permitieron, primero a Ávila Camacho y luego a Miguel Alemán (1946-1952), justificar una serie de cambios en cuanto a la orientación de la política gubernamental respecto de la tenencia de la tierra (Stanford, 1993, p. 192).

En 1941 se autorizaron ejidos colectivos sólo en unas cuantas regiones de México, en virtud de que su organización contradecía el esquema estatal de la modernización agrícola. La defensa del ejido se mantuvo como retórica en el discurso oficial mexicano, al mismo tiempo que el gobierno promovía la parcelación de ejidos, la inversión pública y el crédito subsidiado al sector privado (Stanford, 1993, p. 192). Esto se dio de manera paralela al establecimiento de la política pública conocida como "sustitución de importaciones", al estimularse la producción doméstica de manufacturas.

El gobierno se concentró en mejorar la eficacia agrícola a partir del uso de la tecnología, la capacitación para modernizar la comercialización y distribución, la creación de nuevos proyectos para expandir las tierras cultivables y el ofrecimiento de seguridades a los propietarios individuales para incentivar la inversión (Medina, 1978, pp. 251-260).

Bajo la administración gubernamental de Miguel Alemán, el ataque al ejido se aceleró. Las reformas al artículo 27 constitucional realizadas en diciembre de 1946, recién llegado Alemán a la presidencia de México, amplió la "pequeña propiedad" a 150 hectáreas si éstas se dedicaban al cultivo del algodón (González, 1988, p. 9). En 1948, mediante decreto, se declaró a Baja California como zona de colonización inafectable, "lo que dio lugar a que hubiera obstáculos para una colonización que permitiera asentar a la población rural en forma definitiva y crear explotaciones agrarias para lograr los últimos objetivos de la Reforma Agraria" (López Zamora, 1977, p. 21). 
Braulio Maldonado, primer gobernador constitucional del recién creado estado de Baja California (1953-1959), se lamentaba de no poder repartir tierras entre los braceros que llegaban a la región con la esperanza de trabajar en el estado de California, pues un decreto presidencial lo prohibía en virtud de que había la certeza, por parte del gobierno federal, de que para los años de 1950, ya estaban "satisfechas las necesidades agrarias de Baja California” (Maldonado, 2006, p. 214).

Por eso, cuando en 1946 la Colorado River Land Company vendió al gobierno de México las tierras que aún poseía en el valle de Mexicali, las alrededor de 200000 hectáreas recuperadas para el dominio de la nación no fueron dadas en reparto ejidal. El gobierno de México creó un fideicomiso por medio de la Nacional Financiera con el nombre de Compañía Mexicana de Terrenos del Río Colorado, y de inmediato llevó a cabo contratos con la Comisión Nacional de Colonización que autorizaron la venta con fines de colonización de las tierras recién adquiridas (Herrera, 2002 , pp. 205 y 219). Las tierras se vendieron a agricultores, algunos de los cuales hicieron valer sus derechos como ex aparceros de "la Colorado" (Grijalva, 1978, pp. 140-178). Así, se consolidó una pequeña burguesía agraria, integrada por este sector de pequeños propietarios. ${ }^{15}$ Las tierras así adquiridas recibieron el nombre de "colonias".

En este contexto, la superficie sembrada con algodón en el valle de Mexicali empezó a aumentar de manera constante. Si ya en 1941 la cosecha de algodón había rebasado por primera vez la producción de 100000 pacas, la escasez de este producto en el mercado internacional durante los años de la Segunda Guerra Mundial provocó una demanda inusitada de la fibra, la cual se cotizó a precios cada vez más altos. Las demandas de última hora provocaron que en el valle de Mexicali los precios y sobreprecios se pagaran por encima de las cotizaciones oficiales. La superficie destinada a cultivar el algodón en el valle de Mexicali fue cada vez mayor, al punto que los otros cultivos desaparecieron casi por completo del campo mexicalense. Un testigo de la época lo narra así:

${ }^{15}$ Rigoberto Cárdenas señala que en la legislación mexicana no hay claridad en lo referente a la definición de lo que se considera "pequeña propiedad", pues a pesar de ser una "forma legal de apropiación de la tierra", existen distintos criterios para determinar qué es una pequeña propiedad agrícola (Cárdenas, 1962, p. 46). 
La calentura se volvió fiebre, las tierras sembradas con alfalfa se voltearon para sembrarlas con algodón, se redujeron las áreas de siembra de invierno para no sustraer superficie útil al cultivo de algodón, y se puso fin a los incipientes ensayos que se venían haciendo con siembras de maíz y sorgo. Se corrió la voz de que el valle de Mexicali era "El Dorado" de la leyenda y a él arribaron gente que estaba ansiosa de hacer fortuna (López, E., 1977, p. 60).

La realidad corroboraba esta percepción. En 1954, el valle de Mexicali desplazó a la Comarca Lagunera al producir 434075 pacas de algodón en las 200000 hectáreas sembradas ese año, un promedio de 2.20 pacas por hectárea, conquistando el primer lugar como productor de algodón en la república mexicana (Kerig, 2001, p. 165; Aboites, 2013, p. 401).

\section{¿En La Jabonera se hacía jabón?}

Cuando James Griffin ${ }^{16}$ llegó a Mexicali el 31 de octubre de 1953, para entrevistarse con James Stone, el legendario director de la Compañía Industrial Jabonera del Pacífico, sabía que ésta figuraba entre las mejores de Anderson, Clayton y que la división de California estaba considerada como la más moderna y la mejor manejada de toda la compañía. Griffin había trabajado cerca de siete años con la Anderson, Clayton: primero en Estados Unidos y luego, en los últimos cuatro años, en Argentina y Paraguay, encargado de la operación y construcción de varias despepitadoras así como de la operación de un molino de aceite.

$\mathrm{Al}$ regresar a Estados Unidos, sus jefes, en la oficina principal de la Anderson, Clayton en Houston, Texas, le indicaron que había dos posibilidades de emplearse en México: una en Empalme, Sonora, en un molino de aceite nuevo que estaba en construcción; la otra, en Mexicali, como superintendente de despepitadoras (Grijalva, 2008, p. 27). Para entonces,

${ }^{16}$ James Griffin trabajó para la Anderson, Clayton desde muy joven. Estuvo en La Jabonera entre 1953 y 1971, en donde ocupó responsabilidades de alto nivel, desde la superintendencia de las despepitadoras y del molino de aceite. El testimonio de su experiencia en La Jabonera está narrado en un libro publicado sobre dicha empresa algodonera (véase Grijalva, 2008). 
la Compañía Industrial Jabonera del Pacífico tenía la concentración más grande de despepitadoras a escala mundial.

Griffin arribó a Mexicali cuando se estaba recolectando el algodón del ciclo agrícola 1952-1953 y sus primeras impresiones al recorrer las instalaciones de la Compañía Industrial Jabonera fueron desconcertantes:

Mientras platicábamos notaba el completo desorden en los patios y en las despepitadoras, empezaba a entender por qué nadie había querido enseñarme las plantas. Había basura acumulada adentro y afuera de las plantas, agua tirada en los pisos, muy cerca de los controles eléctricos. Semilla y algodón hueso estaban desparramados en todas partes. De las doce plantas despepitadoras, entre dos y cuatro de ellas, estaban todo el tiempo descompuestas. Nunca vi a las doce trabajando simultáneamente (Grijalva, 2008, p. 31). ${ }^{17}$

Esta situación era producto de la febril actividad llevada a cabo, resultado de la pujanza agrícola vivida en la región. Para la década de los años de 1950, la Compañía Industrial Jabonera del Pacífico había ampliado sus instalaciones al punto de ocupar las 33 hectáreas que originalmente había aportado la Colorado River Land Company en 1925, cuando se organizó la empresa. Había 12 despepitadoras distribuidas en seis edificios, ${ }^{18}$ adonde llegaba el algodón en hueso que era descargado de los camiones procedentes de diferentes partes del valle de Mexicali. Ahí se separaba la semilla del algodón, esto es, se despepitaba el algodón, y con ayuda de sierras y apisonadoras, la fibra salía convertida en una manta esponjosa que se metía en una caja hasta formar una paca. ${ }^{19}$

La paca, una vez terminada, se pesaba y se le ponía una etiqueta numerada - una marca con tinta en la manta en la que se envolvía-, y de

${ }^{17}$ El ingeniero Emilio López Zamora se quejaba de que mientras el gobierno federal y los agricultores de Mexicali llevaban a cabo cuantiosas inversiones tanto en obras hidráulicas como en desmontes y nivelación de tierras, caminos y maquinaria agrícola, las empresas algodoneras tenían obsoletas instalaciones en despepitadoras, molinos de aceite, compresoras, etcétera (López, E., 1977, p. 31).

${ }^{18}$ Había otras dos despepitadoras, llamadas División Pacífico, en las afueras de Mexicali, y otras tres en San Luis Río Colorado, el poblado ubicado en la margen izquierda del Río Colorado, en el estado de Sonora, también parte del delta mexicano del Río Colorado.

${ }^{19}$ Una paca pesa aproximadamente entre 220 y 250 kilos. 
ahí era enviada a los patios de almacenaje al lado de la compresora (Grijalva, 2008, p. 142). Las plantas de despepite son uno de los renglones más importantes de estas empresas agrícolas y la calidad de las máquinas utilizadas para llevar a cabo este proceso influye de manera importante en la calidad del algodón obtenido (López, E., 1977, p. 124).

A esas plantas despepitadoras llegaban los camiones cargados con el algodón pizcado, en esos años manualmente, por cientos de jornaleros agrícolas ${ }^{20}$ — pizcadores- que hacían lo que se considera como uno de los trabajos más duros del campo: arrancar la mota del algodón de la planta para colocarla en las bolsas de ixtle que llevaban al hombro, y que acarreaban a las básculas en donde se pesaba el producto. La mayoría de esos camiones llevaban el algodón cosechado por agricultores refaccionados por la propia Jabonera, pero en ocasiones transportaban también el de otros productores que habían cultivado la fibra con crédito obtenido de otras empresas agrícolas similares ${ }^{21}$ o de instituciones oficiales, como el Banco Nacional de Crédito Ejidal o el de Crédito Agrícola.

También llegaba algodón en hueso en furgones de ferrocarril, que era enviado por la vía ferroviaria que recorría el norte del valle, línea tendida a principios del siglo xx con el nombre de Inter-California Southern Railroad (Kerig, 2001, pp. 81-82).

Una vez que las pacas habían sido clasificadas, se colocaban en los patios de almacenaje. ${ }^{22}$ De la "evaluación" que se hacía a la fibra dependían las ganancias obtenidas en la cosecha, lo que involucraba al agricultor, comprador, exportador y consumidor, en este caso, la industria textil. Cuando la paca salía de la planta despepitadora, se tomaba una muestra de cada lado de la misma y se le ponía una marca con un cupón de etiqueta numerada para su futura identificación. Esto explica la importancia

${ }^{20}$ En este proceso participaban hombres, mujeres y niños, y en ocasiones hasta familias enteras, que a partir de los meses de agosto realizaban esta pesada tarea, bajo un sol incandescente y temperaturas que fluctuaban entre los 40 y 50 grados centígrados.

${ }^{21}$ Ésta fue una de las razones que llevaron a la creación de la Asociación Algodonera de Valle de Mexicali, con la que se protegían de evitar lo que ellos llamaban "algodón de luna”, esto es, que el algodón financiado por una empresa fuera vendido por el agricultor a otra, y así evadir el pago del financiamiento previo.

${ }^{22}$ La clasificación del algodón es aún hoy en día de suma importancia porque es la base de la comercialización de este producto. 
del edificio donde estaba el "cuarto de clasificación de algodón”, y de los clasificadores, hombres expertos en este tipo de tareas. ${ }^{23}$

Al lado de los enormes patios de almacenaje de las pacas estaba el edificio donde éstas se comprimían y preparaban para embarcarse, cuando así lo autorizaba el dueño del algodón. Nos referimos a la compresora responsable, además, del control de las pacas. Con el tiempo, los mecanismos para reducir las pacas evolucionaron al grado de que el tamaño de éstas disminuyó, lo que llevó al ahorro de costos de transporte hacia los mercados nacionales e internacionales. La Jabonera fue una de las primeras empresas agrícolas en introducir maquinaria especializada para producir pacas de alta densidad, compactas y bien prensadas, con lo que se adelantó a las de Estados Unidos. "Probablemente las operaciones de nuestras despepitadoras eran las más modernas del mundo en esos años”, afirma James Griffin (Grijalva, 2008, p. 44).

De la planta salían los camiones cargados con las pacas, pues casi todo el algodón del valle de Mexicali era exportado. Al principio las pacas eran enviadas a California, a los puertos de San Pedro y Long Beach, y durante la década de los años de 1960 a Ensenada, el puerto del Pacífico localizado en el noroeste de Baja California. De esos puertos salían rumbo a Asia, a Japón principalmente.

Estos procesos eran los relacionados con la fibra del algodón, pero otra parte importante de las actividades de este complejo agroindustrial fueron las relativas a la industrialización de la semilla de este producto. El molino de aceite era considerado el corazón de La Jabonera, y sus instalaciones estaban flanqueadas por varias de las bodegas donde se almacenaba la semilla que se obtenía del algodón despepitado. Había varias bodegas de semillas, sólo una de ellas, la Muskogee, techada, pues gracias al clima seco de Mexicali el resto de las bodegas carecían de techo y las semillas estaban al aire libre. ${ }^{24}$

En el molino de aceite, la semilla del algodón era limpiada, desborrada y quebrada para separar la cáscara de la pepita y, para finalmente, extraer

${ }^{23}$ Actualmente la calidad del algodón es clasificada automáticamente por aparatos electrónicos y mecánicos que determinan el color, el contenido de materia extraña, el micro y la longitud de la fibra. La determinación de resistencia ha sido reemplazada con una indicación que se llama "Grams per Tex", que es más precisa (Grijalva, 2008, p. 124).

${ }^{24}$ Los incendios en las bodegas de semillas eran un fenómeno frecuente. 
el aceite a esta última, el cual era posteriormente refinado. El molino, según Enrique Ante, superintendente del mismo, requería de un enjambre de obreros que trabajaban todo el año sin descanso día y noche; distribuidos en varios departamentos, se ayudaban de máquinas que mediante zarandas y succión de aire quitaban a la semilla la mayor parte de las impurezas, y de desborradoras para quitar la borra a la semilla, ${ }^{25}$ además de quebradoras y prensas mecánicas llamadas expellers, con las que la pepita se convertía en aceite. El molino contaba con una planta de solvente, calderas y laboratorio.

Para mediados del siglo pasado, en La Jabonera se procesaban diariamente 400 toneladas de semilla de algodón. El aceite obtenido se almacenaba en enormes tanques, mientras que con el gabazo se hacía una pasta que era enviada al departamento de forrajes en donde se molía y se convertía en harinolina, un excelente alimento para el ganado (Grijalva, 2008, p. 199).

Un edificio de cuatro pisos, de ladrillo y concreto, era la planta de productos terminados, también llamada "refinería", que llegó a ser el más prominente y costoso inmueble de La Jabonera. Ahí se instalaron maquinaria y equipo novedoso para, además de refinar el aceite del algodón, llevar a cabo la deodorización, blanqueo e hidrogenización del aceite y el empaque de productos. Desde los primeros años, La Jabonera produjo jabón, grasas vegetales y aceites de semilla de algodón crudo, refinado e hidrogenado. La manteca vegetal INCA se empacaba en bolsas de plástico y el aceite se envasaba en botellas también de plástico.

En los confines de este complejo estaban los corrales para la engorda del ganado que era llevado al lugar para aprovechar la harinolina que se producía con la cascarilla de la semilla. En otro de los linderos estaban las casas donde vivían los obreros con sus familias, principalmente los que habían llegado en 1925 con Brittingham. La Jabonera era un espacio cerrado - una especie de campamento, delimitado por una cerca- al que sólo se podía tener acceso mediante un puente peatonal y de autos que se cerraba por la noche. Muchos de los obreros de La Jabonera trabajaban y vivían ahí con sus familias. En las tres casas construidas por los tres hijos de Brittingham vivían el director y los dos funcionarios de más alto rango después de éste.

${ }^{25}$ En el molino llegó a haber 84 máquinas desborradoras. 
La concentración de la mayor parte de las actividades de esta empresa agrícola en el espacio urbano y el movimiento natural de este tipo de industria terminaron por ocasionar un caos que afectaba las actividades cotidianas de la población mexicalense. Como superintendente de las despepitadoras, James Griffin se enfrentó a una situación difícil, pues fue muy evidente la imposibilidad de operar de manera eficiente las 12 despepitadoras de La Jabonera. "En ninguna parte del mundo había tantas plantas juntas", reflexionó 45 años después. "Aparte de todo esto, la mayoría de estas plantas eran muy viejas, algunos dirían obsoletas”, concluía (Grijalva, 2008, p. 39).

Debido a esto, y por iniciativa del entonces superintendente, se aprobó un programa de modernización de las instalaciones con el fin de establecer nuevas plantas despepitadoras en diversos puntos del valle de Mexicali; en realidad, se contemplaba cerrar paulatinamente las plantas existentes. A la vuelta de los años, a finales de la década de 1960, La Jabonera tenía 17 despepitadoras distribuidas en el valle de Mexicali. En la ciudad, en las instalaciones originales, sólo quedaron dos. ${ }^{26}$ La desconcentración de las despepitadoras facilitó la entrega del algodón recolectado en los campos agrícolas de los ejidos y colonias, evitando que los agricultores tuvieran que viajar a la ciudad con ese propósito, en donde tenían que permanecer por días o hasta semanas para entregar el algodón en hueso.

\section{A manera de conclusiones}

El caso aquí descrito, el de la Compañía Industrial Jabonera del Pacífico, es el de una empresa agroindustrial algodonera que ejerció un importante control sobre el proceso productivo agrícola en el valle de Mexicali, desde la década de 1940 hasta principios de 1970. Desde el financiamiento a los agricultores para que cultivaran la malvácea, mecanismo eficaz para asegurarse la materia prima, hasta el establecimiento de una infraestructura adecuada para la industrialización de la semilla del algodón, por un lado, y la comercialización de la fibra para el mercado textilero foráneo, por el otro, esta empresa vigiló con celo las distintas etapas de la producción del

${ }^{26}$ Éstas fueron modernizadas con secadoras, limpiadoras de fibra, cajas de más capacidad y prensas de alta densidad (Grijalva, 2008, p. 157). 
algodón, reproduciendo mecanismos que la corporación a la que pertenecía, la Anderson, Clayton ("la Clayton"), llevaba a cabo en otras partes de México y de América Latina.

La Jabonera era ya la principal comercializadora del algodón en Mexicali en 1941. En noviembre de ese año registró una producción de 38680 pacas, contra 20000 de la Algodonera del Valle y 8000 de la Despepitadora Mexicali (Aboites, 2013, p. 252); en ese año, el total obtenido fue de 65000 pacas (López, E., 1977, p. 63). Para mediados de la década siguiente, en el ciclo 1954-1955, La Jabonera acaparó $47.81 \%$ de la cosecha, y en los ciclos 1965-1966 y 1966-196727 —que establecieron récords de producción-, su participación fue de $37.89 \%$ y $34.26 \%$, respectivamente (Grijalva, 2008, p. 129).

Hemos intentado delinear, a grandes rasgos y desde su surgimiento, las principales características de una empresa algodonera que participó, con otras similares del ramo, de la prosperidad derivada del boom algodonero en el valle de Mexicali, bonanza en la que La Jabonera tuvo una participación directa. Salvo una, cuyo capital era mexicano, todas esas corporaciones eran extranjeras. Llegaron a ser 17 y la mayoría entró a la industria algodonera regional durante la década de los años de 1950.

Formaron la Asociación Algodonera del Valle de Mexicali, mediante la cual crearon alianzas para proteger el mercado y limitar riesgos de inversión; al mismo tiempo, tuvieron un papel activo en la política local. Sus directivos participaron en el sistema bancario regional, en calidad de integrantes de los consejos de administración de los bancos locales: James Stone, director de La Jabonera, que llevó las riendas de la empresa desde la década de 1930 hasta su jubilación en el año de 1966, era presidente del Consejo de Administración del Banco de Comercio en Baja California. ${ }^{28}$ El liderazgo empresarial de La Jabonera era indiscutible.

${ }^{27}$ En estos ciclos, la cosecha en el valle de Mexicali fue de 530226 y de 542 279, respectivamente, y la participación de La Jabonera fue con 201094 y 185774 pacas (Grijalva, 2008, p. 129).

${ }^{28} \mathrm{Al}$ interior de las instalaciones de La Jabonera había una sucursal del Banco de Comercio. Esta institución bancaria, cuyo director fue Manuel Espinosa Yglesias, era la más importante de México en ese momento. En 1963, Espinosa se convirtió también en el director de la Fundación Mary Street Jenkins, que heredó las acciones de la Colorado River Land Company en la Compañía Industrial Jabonera del Pacífico. 
Desde sus orígenes como espacio dedicado al cultivo del algodón, el valle de Mexicali experimentó los adelantos tecnológicos de los países industrializados. La mecanización temprana de sus procesos agrícolas lo colocó en una situación de ventaja frente a otros espacios similares. El hecho de que una parte del algodón fuera colocado en el mercado internacional, ha dado lugar a que algunos estudiosos del tema hayan recurrido al concepto de "enclave" para explicar el desarrollo agrícola de la región (Kerig, 2001).

Sin embargo, consideramos que ese enfoque es limitado, pues habría que considerar la posición estratégica del valle de Mexicali, su condición fronteriza y la importancia que tuvo para su desarrollo la cercanía geográfica con una economía avanzada como es la de Estados Unidos (Cerutti, 2001, p. 295). Esto nos ayudaría a entender los ritmos y las características de su expansión productiva, su repercusión en la ampliación de su frontera agrícola mediante la incorporación de nuevos predios y el desarrollo de infraestructura hidráulica, con el fin de satisfacer las exigencias del mercado externo (Cerutti, 1994, p. 113).

El surgimiento de las fibras sintéticas, los problemas derivados de la explotación indiscriminada de la tierra, la aparición de plagas depredadoras que minaron los índices de producción agrícola ${ }^{29}$ y el aumento de los niveles de salinidad en las aguas del Río Colorado contribuyeron a que el "oro blanco" dejara de ser un cultivo redituable en el valle, sobreviniendo el colapso.

James Griffin lo recuerda así:

A partir de la primavera de 1970, la situación en La Jabonera se hizo crítica. En las tres cosechas anteriores, la producción algodonera del valle de Mexicali había bajado drásticamente y, peor aún, el porcentaje que La Jabonera manejaba era cada vez menor [...] La disminución de volumen en las despepitadoras se reflejaba en las otras dependencias; hubo menos pacas que almacenar y que embarcar, menos semillas para procesar en el molino y menos aceite para refinar en la planta de productos terminados (Grijalva, 2008, p. 224).

${ }^{29}$ El gusano rosado hizo estragos en las cosechas de algodón y no hubo manera efectiva de controlarlo. La plaga bajó la producción y aumentó el costo por hectárea sembrada debido al precio de la fumigación, haciendo incosteable el cultivo del producto. 
No obstante, algunas empresas sobrevivieron y aún permanecen en la región, en donde se cultivan entre 25000 y 30000 hectáreas de algodón. Debido al aumento del precio internacional del algodón, en 2011 se cultivaron 39000 hectáreas de algodón y se calcula que la producción fue de más de 200000 pacas, enviadas a China, Japón y Estados Unidos. "La mayoría se vende a la empresa Royo Cotton, que se queda con 70 u $80 \%$ del algodón del valle de Mexicali y el resto se queda en el mercado nacional" (Ortiz, 2012, p. 14). Algunas zonas del valle de Mexicali volvieron a cubrirse de blanco como en los viejos tiempos, y los caminos del valle fueron de nuevo recorridos por camiones de racas con el algodón cosechado a bordo, que ya no se pizca manualmente sino con modernas máquinas.

En 2012, agricultores mexicalenses festejaron el centenario del inicio del cultivo del algodón en el lugar. Hubo alborozo y alegría entre ellos porque vislumbraron un futuro prometedor debido al aumento del precio internacional de la fibra. El problema principal ahora es el agua, que no alcanza para todos, pues en la actualidad el Río Colorado no sólo alimenta a la ciudad y valle de Mexicali, sino que a través de un moderno acueducto surte a las poblaciones de Tijuana y Tecate; además, es llevada al otro lado de la frontera para suministrar líquido al condado de San Diego, en el suroeste de California.

¿Volverá el auge algodonero al valle de Mexicali? Es probable que no, porque las condiciones estructurales desde la perspectiva económica no son las mismas. El agua, antes abundante, ahora es un bien restringido. Cultivos como el espárrago y el cebollín tienen un importante lugar en el mercado internacional. Los mecanismos para refacción y avío ya no son los mismos. Habría que vigilar el desempeño futuro de este cultivo.

\section{Bibliografía}

Aboites, L. (2013). El norte entre algodones. Población, trabajo agrícola y optimismo en México, 1930-1970. México: El Colegio de México.

Aboites, L. (1991a). Cuentas del reparto agrario norteño 1920-1940. México: Centro de Investigaciones y Estudios Superiores en Antropología Social.

Aboites, L. (1991b). El valle de Mexicali, 1930-1934: política agraria, crisis económica y conflicto fraccional. En Memoria del XV Simposio de Historia y Antropología, vol. 1 (pp. 509-526). Universidad de Sonora, Sonora. 
Anderson, T. D. (2010). Anderson, Clayton and Company. Recuperado del sitio de internet de la Texas State Historical Association: <www.htpp//tshonline.org/ handbook/online/articles/dia01>.

Anguiano, M. E. (1992). Irrigación y capital para transformar el desierto. La formación social del valle de Mexicali a principios del siglo xx. Frontera Norte, 4(8), 125-148.

Barragán, J. I. y Cerutti, M. (1993). Juan F. Brittingham y la industria en México, 1859-1940. Monterrey: Urbis Internacional.

Berumen, M. Á. (2013). La conquista del agua y del imaginario. Mexicali y Valle Imperial, 1901-1916. México: Cuadro x Cuadro, Consejo Nacional para la Cultura y las Artes, Fondo Nacional para la Cultura y las Artes.

Bistráin, P. (1953). Estudio sobre los coeficientes de riego del Distrito de Riego del Río Colorado, Baja California, y problemas que afectan su operación. Ingeniería Hidráulica, 7(1), 35-65.

Cárdenas, R. (1962). La reforma agraria y el problema salino en el valle de Mexicali (Tesis de licenciatura en Derecho). Universidad Nacional Autónoma de México, México.

Case, C. (1929). Readjustments in post-war cotton culture. Economic Geography, 5(4), 335-347.

Cerutti, M. (2001). Frontera y desarrollo empresarial en el norte de México (18501910) [Número especial]. Frontera Norte, 13(2), 283-301.

Cerutti, M. (1994). Empresarios y sociedades empresariales en el norte de México (1870-1920). Revista de Historia Industrial, (6), 95-116.

Colby, B. G. y Jacobs, K. L. (Ed.). (2007). Arizona water policy: management innovations in a urbanizing arid region. Washington: Resources for the Future.

Dicken, S. H. (1938). Cotton regions of Mexico. Economic Geography, 14(4), 363371.

Dipp, A. (2002). Alfredo Dipp/Entrevistador: Aidé Grijalva. Mexicali, Baja California.

Herrera, P. (2002). Reconquista y colonización del valle de Mexicali y otros escritos paralelos. Mexicali: Universidad Autónoma de Baja California, XVII Ayuntamiento de Mexicali, Instituto de Cultura de Baja California.

Hendricks, W. O. (1996). Guillermo Andrade y el desarrollo del delta mexicano del Río Colorado, 1874-1905. Mexicali: Secretaría de Educación Pública, Universidad Autónoma de Baja California.

Hundley, N. (2000). Las aguas divididas. Un siglo de controversia entre México y Estados Unidos. Mexicali: Universidad Autónoma de Baja California, Comisión Nacional del Agua.

Jiménez, V. y Dipp, A. (Comps.). (2003). Mexicali constructores. Mexicali: Algibe Editorial. 
Kerig, D. P. (2001). El valle de Mexicali y la Colorado River Land Company, 19021946. Mexicali: XVI Ayuntamiento de Mexicali, Universidad Autónoma de Baja California.

González, G. (1988). El sistema de contratación de los trabajadores migrantes en la región costa-centro de Sonora, Hermosillo-Empalme, 1949-1962 (Tesis de licenciatura en Sociología). Universidad de Sonora, Hermosillo, Sonora.

Grijalva, A., Niño, L. y Arriaga, R. (2012). Braceros fuimos y a vivir aquí nos quedamos. Migración y frontera. En J. A. Moreno, A. Sández y M. G. López (Coords.), Éxodos, veredas y muros. Perspectivas sobre la migración (pp. 229-282). Mexicali: Instituto de Investigaciones Sociales, Universidad Autónoma de Baja California.

Grijalva, A. (Coord.). (2008). Aquellos años del algodón, La Jabonera y el valle de Mexicali. Mexicali: Universidad Autónoma de Baja California, Urbi Residencial, Hermosillo y Asociados Arquitectos, S. C., Fábrica de Papel San Francisco, Grupo Desarrollador IAmsa, Nutrimentos Mexicanos, S. A. de C.V., XIX Ayuntamiento de Mexicali.

Grijalva, A. (1978). El desarrollo del capitalismo en el valle de Mexicali (Tesis de maestría en Sociología). Facultad Latinoamericana de Ciencias Sociales, México.

López, A. (1 de septiembre de 1961). Tercer Informe Presidencial. Diario de Debates de la Cámara de Diputados del Congreso de los Estados Unidos Mexicanos, XLV Legislatura, pp. 118-183.

López, E. (1977). El agua, la tierra. Los hombres de México. México: Fondo de Cultura Económica.

Maldonado, B. (2006). Los inconformes. Baja California. Comentarios políticos y otras obras selectas (pp. 169-235). Mexicali: Instituto de Investigaciones Históricas, Universidad Autónoma de Baja California.

Medina, L. (1978). Del cardenismo al avilacamachismo. México: El Colegio de México. Musoke, M. S. y Olmstead, A. L. (1982). The rise of the cotton industry in California: A comparative perspective. The Journal of Economic History, 42(2), $385-412$.

Ortiz, M. (2012). Cien años cultivando y cosechando el oro blanco. [Suplemento Especial]. La Crónica de Baja California.

Rubio, C. A. (2007). A la vera del Colorado. Reminiscencias. Mexicali: Familia Rubio Díaz, Instituto de Investigaciones Históricas, Universidad Autónoma de Baja California.

Secretaría de Agricultura y Fomento (SAF). (1939). Cultivo y comercio del algodón en México. México: Dirección de Economía Rural.

Stanford, L. (1993). The 'organization' of Mexican agriculture: Conflicts and compromises. Latin American Research Review, 28(1), 188-201. 
Aidé Grijalva / Agroindustria y algodón en el valle de Mexicali. La Compañía Industrial Jabonera del Pacífico

Singleton, J. (1998). Planning for cotton, 1945-1951. The Economy History Review, 43(1), 62-78.

Vargas-Lobsinger, M. (1999). La Comarca Lagunera. De la Revolución a la expropiación de las haciendas, 1910-1940. México: Universidad Nacional Autónoma de México, Instituto Nacional de Estudios Históricos de la Revolución Mexicana.

Walsh, C. (2007). Un risueño porvenir. Algodón y desarrollo regional en la frontera norte mexicana, 1920-1965. En F. J. Gómez C. (Ed.), Paisajes mexicanos de la reforma agraria. Homenaje a William Roseberry (pp. 97-132). México: El Colegio de Michoacán, Benemérita Universidad Autónoma de Puebla, Consejo Nacional de Ciencia y Tecnología. 